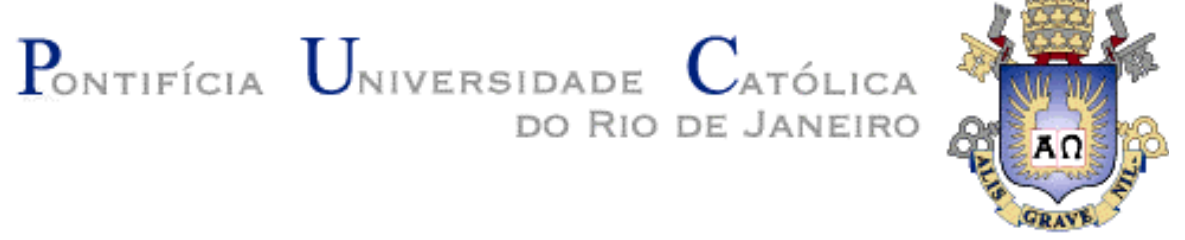

Julio Ernesto Macías Alvarenga

\title{
MODELAGEM NUMÉRICA DO TRANSPORTE DE VÍRUS EM AQÜÍFEROS FRATURADOS - POROSOS
}

\begin{abstract}
Tese de Doutorado
Tese apresentada ao Programa de Pós-graduação em Engenharia Civil da PUC-Rio como requisito parcial para obtenção do título de Doutor em Engenharia Civil.

Orientador: Eurípedes do Amaral Vargas Jr.
\end{abstract}

Rio de Janeiro

Abril de 2008 
Julio Ernesto Macías Alvarenga

\section{Modelagem Numérica do Transporte de Vírus em Aqüíferos Fraturados - Porosos}

Tese apresentada ao Programa de Pós-graduação em Engenharia Civil da PUC-Rio como requisito parcial para obtenção do título de Doutor em Engenharia Civil. Aprovada pela Comissão Examinadora abaixo assinada.

Eurípedes do Amaral Vargas Jr. Orientador

Departamento de Engenharia Civil - PUC-Rio

Luiz Fernando Campos Ramos Martha Departamento de Engenharia Civil - PUC-Rio

Denise Maria Mano Pessoa Departamento de Engenharia Civil - PUC-Rio

Roberto Francisco de Azevedo Departamento de Engenharia Civil - UFV

João Luiz Elias Campos Consultor

José Eugênio Leal Coordenador Setorial do Centro

Técnico Científico - PUC-Rio

Rio de Janeiro, 07 de Abril de 2008 
Todos os direitos reservados. É proibida a reprodução total ou parcial do trabalho sem autorização da universidade, do autor e do orientador.

\section{Julio Ernesto Macías Alvarenga}

Geólogo graduado pela Universidade da Costa Rica. Mestrado em Engenharia Civil na área de geotecnia pela Pontifícia Universidade Católica do Rio de Janeiro.

Ficha Catalográfica

Macías, Julio E.

Modelagem Numérica do Transporte de Vírus em aqüíferos fraturados - porosos / Julio E. Macías Alvarenga; orientador: Eurípedes do Amaral Vargas Jr. - Rio de Janeiro: PUC, Departamento de Engenharia Civil, 2008.

257 f.: il. ; $29,7 \mathrm{~cm}$

Tese (doutorado) - Pontifícia Universidade Católica do Rio de Janeiro, Departamento de Engenharia Civil.

Inclui referências bibliográficas.

1. Engenharia Civil - Teses. 2. Transporte de vírus. 3. Aqüífero fraturado - poroso. 4. Fluxo saturado-não saturado. 5. Modelagem numérica. I. Vargas júnior, Eurípedes do Amaral. II. Pontifícia Universidade Católica do Rio de Janeiro. Departamento de Engenharia Civil. III. Título. 


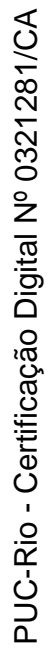

Dedicatória:

A mis padres, por el dón de la vida y por la lucha constante de buscar lo mejor para sus hijos, especialmente em los tiempos de guerra. 


\section{AGRADECIMENTOS}

Ao professor Eurípedes Vargas pela amizade e pela orientação durante a realização desta pesquisa.

A Olga pelo amor e carinho.

Aos colegas da PUC, Tiago, Favio, Luciana, Wagner, Roberto, Marcelo, Juan Pablo, Marlesu, pela amizade e pelos ensinamentos de vida.

Aos amigos Daniel, Johanna,Sergio, pelo convívio.

As instituições que financiaram esta pesquisa, CAPES, CNPq e TECGRAF. Ao povo brasileiro pela oportunidade de desenvolver uma pesquisa que era do meu intresse fazia um bom tempo. Muito Obrigado! 


\section{Resumo}

Macías, Julio E.; Vargas Jr, Eurípedes do Amaral. Modelagem Numérica do Transporte de Vírus em Aqüíferos Fraturados - Porosos. Rio de Janeiro, 2008. 252p. Tese de Doutorado - Departamento de Engenharia Civil, Pontifícia Universidade Católica do Rio de Janeiro.

A avaliação do potencial de contaminação de capatações de água, por causa das águas residuais provenientes dos sistemas de tanque séptico, é feita a partir da definição da distância de separação mínima que deve existir entre a captação e o local de infiltração do efluente. A determinação dessa distância define a zona de proteção da captação. Existem três metodologias para definir o tamanho dessa zona de proteção: metodologias baseadas em distâncias fixas e tempos de trânsito, metodologias baseadas na vulnerabilidade e metodologias baseadas no risco de infecção.

No caso da Costa Rica, as avaliações são feitas através do uso da metodologia baseada no tempo de trânsito. O tempo de trânsito empregado corresponde ao tempo de sobrevivência dos vírus. Nesta análise determina-se a distância máxima percorrida pelos vírus durante esse tempo, e essa distância define a separação mínima. Esse método considera que o transporte ocorre por percolação vertical saturada através da zona não saturada, e por transporte ao longo da interface água-ar na zona saturada segundo o gradiente natural.

Neste trabalho apresenta-se um novo procedimento, baseado no risco de infecção, para a determinação da distância de separação considerando os efeitos da saturação variável e o fraturamento. Este procedimento determina a distância máxima percorrida, a partir do cálculo das concentrações de vírus. A distância de separação mínima corresponde à distância entre a fonte de injeção e o ponto aonde a concentração atinge o valor máximo de concentração permitida. Para o desenvolvimento deste novo procedimento foi implementado um código de programação que inclui: fluxo saturado-não saturado e transporte explícito nos poros e nas fraturas, advecção, dispersão, decaimento, sorção na superfície dos sólidos, sorção nas interfaces água-ar e água-sólido, filtração mecânica e exclusão de poros. 
Foi realizada uma análise comparativa entre as metodologias acima descritas para três geometrias tipo representativas das condições estratigráficas de algumas áreas do Vale Central da Costa Rica. Os resultados obtidos indicaram que a metodologia normalmente empregada na Costa Rica pode ser inadequada para prever na maioria dos casos a possibilidade de contaminação.

\section{Palavras-chave}

Transporte de vírus, Aqüífero fraturado - poroso, Modelagem numérica, Fluxo saturado-não saturado. 


\section{Abstract}

Macías, Julio E.; Vargas Jr, Eurípedes do Amaral. Numerical Modeling of Virus Transport in Fractured-Porous Media. Rio de Janeiro, 2008. 252p. Ph.D. Thesis - Departamento de Engenharia Civil, Pontifícia Universidade Católica do Rio de Janeiro.

Setback distances of wellhead and catchments from septic tanks are establised by three aproaches: methods based on fixed setback distances or fixed travel times; methods based on vulnerability analysis and methods based on infection risk.

In Costa Rica, the determination of setback distances is based on fixed travel times. This approach considers that during and specified travel time all microorganisms will be inactivated, and that the distance traveled during this time defines the minimum safe separation. In this approach a unitary hydraulic gradient and saturated hydraulic conductivity are considered for transport in the unsaturated zone and the natural hydraulic gradient and saturated conductivity for transport in the saturated zone. Only advection is considered as the responsible mechanism for virus transport.

A new procedure is presented in this document to define the setback distance. This procedure is based on the infection risk approach. According to this approach the minimum required setback distance is defined as the distance between the injection point and the location where the contaminant reaches a maximum allowable concentration. This procedure was implemented in a computer code that considers variable saturated water flow, fractured-porous media, advection, dispersion, dynamic sorption, inactivation and mechanical filtration.

A comparative analysis was performed for three hypothetical geometries using the two approaches described. The results indicate the approach normally used in Costa Rica may no reproduce adequately the possibility of catchments and wellhead contamination.

\section{Keywords}

Virus transport, fractured-porous aquifers, numerical modeling, variably saturated water flow. 


\section{Sumário}

Resumo 1

Palavras-chave 2

$\begin{array}{ll}\text { Abstract } & 3\end{array}$

Keywords 3

1 Apresentação 13

1.1. Motivação 13

1.2. Metodologia de Trabalho 14

1.3. Estrutura do Documento 16

2 Introdução 19

2.1. Zonas de Proteção 26

2.2. Aqüíferos 28

2.3. Modelos Conceituais 31

2.3.1. Modelos Conceituais para o Fluxo em Saturação Variável 31

2.3.2. Modelos Conceituais para o transporte de poluentes 37

2.4. Modelos Matemáticos 38

2.5. Revisão da aplicação dos Modelos para Fluxo e Transporte 42

2.5.1. Contínuo - Contínuo Equivalente 43

2.5.2. Contínuo - Contínuo Equivalente com porosidade composta 45

2.5.3. Dupla Porosidade e Dupla Permeabilidade 45

2.5.4. Fraturado Discreto $\quad 47$

2.5.5. Fraturado Poroso $\quad 47$

2.6. Revisão dos modelos de transporte de vírus 48

2.7. Literatura Nacional 50

2.8. Objetivos $\quad 51$ 
3 Vírus $\quad 54$

3.1. Vírus 57

3.2. Fatores que regulam a sobrevivência 60

3.3. Transporte de Vírus 63

3.3.1. Adveção - Dispersão 63

3.3.2. Inativação 67

3.3.3. Sorção 68

3.3.4. Filtração (Straining) 73

4 Equações do Problema e Solução Numérica 85

4.1. Equações do Fluxo 85

4.2. Equações do Transporte de Vírus 86

4.3. Discretização das Equações 89

4.4. Programa VirTran-3D 91

5 Validação Numérica $\quad 97$

5.1. Validação Numérica do Fluxo 98

5.1.1. Fluxo em Regime Saturado 99

5.1.2. Fluxo em Regime Não Saturado 99

5.2. Validação Numérica do Transporte 100

5.2.1. Transporte em Regime Saturado 100

5.2.2. Transporte em Regime Não Saturado 107

5.3. Outras verificações numéricas 110

6 Análise Comparativa: Aqüíferos do Vale Central 113

6.1. Aqüíferos na Grande Área Metropolitana 118

6.2. Geometrias Tipo 120

6.3. Análise do Transporte - MTAv 125

6.4. Análise do Transporte - Programa VirTran-3D 127

6.5. Análise dos Resultados e Comparação das Metodologias 135

7 Conclusões e Sugestões $\quad 141$

7.1. Conclusões 141 
8 Referências Bibliográficas

APÊNDICE A: Equações Governantes do Problema 163

A.1. Equações que descrevem o Fluxo 163

A.1.1. Fluxo na Matriz 163

A.1.2. Fluxo na Fratura $\quad 169$

A.2. Equações que descrevem o transporte de vírus 172

A.2.1. Transporte na Matriz 172

$\begin{array}{ll}\text { A.2.2. Transporte na Fratura } & 178\end{array}$

APÊNDICE B: Método dos Volumes Finitos (MVF) 184

B.1. Generalidades do MVF 184

B.2. Interpolação e Fluxos nas Interfaces 191

B.3. Condições de Contorno 193

APÊNDICE C: Solução Numérica - Equação de Fluxo na Matriz 194

C.1. Construção do Volume de Controle 194

C.2. Discretização Espacial 196

C.3. Efeito do Contorno 200

C.4. Equação Resultante da Discretização Espacial 203

C.5. Discretização Temporal 203

APÊNDICE D: Solução Numérica - Equação de Fluxo na Fratura 205

D.1. Construção do Volume de Controle 205

D.2. Discretização Espacial 207

D.3. Efeito do Contorno 210

D.4. Equação Resultante da Discretização Espacial 212

D.5. Discretização Temporal 213

APÊNDICE E: Solução Numérica - Equação de Transporte na Matriz 215

E.1. Construção do Volume de Controle 215

E.2. Discretização Espacial 217 
E.3. Efeito do Contorno 223

E.4. Equação Resultante da Discretização Espacial 226

E.5. Discretização Temporal 226

APÊNDICE F: Solução Numérica - Equação de Transporte na Fratura 228

F.1. Construção do Volume de Controle 228

F.2. Discretização Espacial 230

F.3. Efeito do Contorno 234

F.4. Equação Resultante da Discretização Espacial 236

F.5. Discretização Temporal 237

APÊNDICE G: Solução Numérica - Equações Complementares 239

G.1. Equações da Matriz 239

G.2. Equações da Fratura 240

APÊNDICE H: Função de Interpolação Exponencial 243

Anexo 1: Soluções Analíticas 249

An.1. Fluxo Saturado Unidimensional em Regime Transiente 249

An.2. Transporte unidimensional de vírus no meio poroso saturado 249

An.3. Transporte unidimensional de colóides numa fratura saturada com abertura constante 


\section{Lista de figuras}

Figura 2.1. Esquema do Sistema de Tratamento por Tanque Séptico. 22

Figura 2.2. Esquema gráfico para o cálculo da distância de separação. 25

Figura 2.3. Tipos de vazios: poros e fraturas 29

Figura 2.4. Perfil Esquemático dos Aqüíferos Livre e Confinado 30

Figura 2.5. Efeito da Saturação na Fratura. 33

Figura 2.6. Modelo do Fluxo Pelicular na Fratura 33

Figura 2.7. Modelos Conceituais para Aqüíferos Porosos e Fraturados. 36

Figura 2.8. Esquema gráfico da função composta para a permeabilidade do meio equivalente. 39

Figura 3.1. Tamanhos Característicos de Partículas e Poros 58

Figura 3.2 Estrutura de um Vírus Bacteriófago 58

Figura 3.3. Esquema conceitual do fenômeno de exclusão 64

Figura 3.4. Mecanismos de Sorção e Filtração. 69

Figura 3.5. Mecanismos de Colisão da Teoria da Filtração Coloidal $\quad 70$

Figura 5.1. Geometria para a validação bidimensional. 98

Figura 5.2. Geometria para a validação tridimensional. 98

Figura 5.3 Fluxo Transiente Saturado - Comparação dos Resultados. 99

Figura 5.4 Fluxo Transiente não Saturado - Comparação dos

Resultados.

100

Figura 5.5 Transporte Caso I com condição de Tipo Dirichlet 102

Figura 5.6 Transporte Caso I com condição de Tipo Neuman 102

Figura 5.7 Transporte Caso II com condição de Tipo Dirichlet 103

Figura 5.8 Transporte Caso II com condição de Tipo Neuman 103

Figura 5.9 Transporte na Fratura com condição de Tipo Dirichlet 105

Figura 5.10 Transporte na Fratura com condição de Tipo Neuman 105

Figura 5.11 Geometria do Meio Fraturado - Poroso. 106

Figura 5.12 Transporte no Meio Fraturado-Poroso com condição de Tipo Dirichlet

Figura 5.13 Transporte no Meio Fraturado-Poroso com condição de Tipo Neuman. 
Figura 5.14 Transporte no Meio Poroso em condição de fluxo permanente não saturado.

Figura 5.15 Transporte no Meio Poroso sob condição de fluxo em saturação variável. Variação da carga de pressão no ponto de observação.

Figura 5.16 Transporte no Meio Poroso sob condição de fluxo em saturação variável. Variação da concentração no ponto de observação.110 Figura 5.17 Comparação das curvas de concentração para transporte advectivo-dispersivo com exclusão e sem exclusão

Figura 5.18 Comparação das curvas de concentração para transporte advectivo-dispersivo com sorção e sem sorção na interface água-ar. 112 Figura 6.1 Variação da Concentração Segundo o MTAv 114 Figura 6.2 Variação da Concentração Segundo a Metodologia Baseada no Risco

Figura 6.3 Localização do Vale Central da Costa Rica 118

Figura 6.4 Estratigrafia dos Aqüíferos do Vale Central da Costa Rica 120 Figura 6.5 Geometrias Tipo. 121

Figura 6.6 Estratigrafia e Parâmetros da Geometria 1. 122

Figura 6.7 Modelo Hidrogeológico da Geometria 1. 122

Figura 6.8 Estratigrafia e Parâmetros da Geometria 2 123

Figura 6.9 Modelo Hidrogeológico da Geometria 2. 123

Figura 6.10 Estratigrafia e Parâmetros da Geometria 3. 124

Figura 6.11 Modelo Hidrogeológico da Geometria 3. 124

Figura 6.12. Resultados das Análises da Geometria 1.

Figura 6.13. Resultados das Análises da Geometria 2. 133

Figura 6.14. Resultados das Análises da Geometria 3.

Figura A1. Volume de Referência no Meio Poroso.

Fluxo Unidimensional 163

Figura A2. Volume de Referência no Meio Poroso.

Fluxo Tridimensional 164

Figura A3. Volume de Referência na Fratura. Fluxo Tridimensional 170 
Figura A4. Volume de Referência no meio poroso.

Transporte Unidimensional

Figura A5. Volume de Referência no Meio Poroso.

Transporte Tridimensional

Figura A6. Volume de Referência na Fratura.

Transporte Tridimensiona

Figura B1. Esquema de armazenamento (modificado de Barth T. e Ohlberger, 2004)

Figura B2. Volume de Controle e subvolumes de controle para o nó 1. 187

Figura C1. Subvolume de controle para o nó i, planos internos. 195

Figura C2. Subvolume de controle para o nó i, planos externos. $\quad 195$

Figura D1. Volume de controle para o nó i. 206

Figura E2. Subvolume de controle para o nó i, planos externos. $\quad 217$

Figura F1. Volume de controle para o nó i. 229

Figura H1. Sistemas de Coordenadas para a aplicação da função de interpolação exponencial.

Figura H2. Exemplo de Aplicação. 


\section{Lista de tabelas}

Tabela 3.1. Concentrações médias em efluentes domésticos

Tabela 3.2 Remoção de vírus e bactérias para diferentes sistemas de tratamento

Tabela 3.3. Concentrações de microorganismos em águas residuais domésticas cruas e no efluente secundário 56

Tabela 3.4 Tamanhos característicos de alguns microorganismos

Tabela 3.5. Doenças e organismos geradores

Tabela 3.6 Fatores que influenciam na sobrevivência das bactérias no solo

Tabela 3.7. Fatores que influenciam na sobrevivência e transporte dos vírus no solo.

Tabela 3.8. Tempos de sobrevivência dos organismos patogênicos

Tabela 3.9 Taxas de Inativação para as fases líquida $\left(\mu_{1}\right)$ e sorvida $\left(\left(\mu_{\mathrm{s}}\right)\right.$, valores de Campo.

Tabela 3.9 Taxas de Inativação para as fases líquida $\left(\mu_{1}\right)$ e sorvida $\left(\left(\mu_{\mathrm{s}}\right)\right.$, valores de Laboratório.

Tabela 3.10 Taxas de adsorção e desorção em meios porosos, valores para alguns vírus e colóides em condições de campo.

Tabela 3.10 Taxas de adsorção e desorção em meios porosos, valores para alguns vírus e colóides em condições de laboratório.

Tabela 3.11 Taxas de adsorção de colóides em fraturas, valores para condições de laboratório.

Tabela 3.12 Valores da eficiência da captura para meios porosos em condições de laboratório.

Tabela 3.13 Valores da eficiência da captura para meios porosos em condições de campo.

Tabela 3.14 Taxas de adsorção e desorção para meios porosos não saturados sob condições de laboratório. 
Tabela 3.15 Taxas de filtração em meios porosos sob condições de campo e laboratório.

Tabela 6.1 Velocidades de Percolação - MTAv. 126

Tabela 6.2 Cálculos Intermediários - MTAv. 126

Tabela 6.3 Distâncias Percorridas - MTAv. 127

Tabela 6.4 Informações sobre as malhas geradas. 127

Tabela 6.5 Condições de contorno para a simulação do fluxo. 129

Tabela 6.6 Tempos de Processamento computacional para os casos da Geometria 1.

Tabela 6.7 Tempos de Processamento computacional para os casos da Geometria 2.

Tabela 6.8 Tempos de Processamento computacional para os casos da Geometria 3.

Tabela 6.9 Distâncias percorridas para os casos da Geometria 1. 131

Tabela 6.10 Distâncias percorridas para os casos da Geometria 2. 131

Tabela 6.11 Distâncias percorridas para os casos da Geometria 3. 131

Tabela 6.12. Distâncias percorridas normalizadas com

os valores do método MTAv.

Tabela 6.13. Distâncias percorridas normalizadas com os valores do método MTAv. 